\title{
Risk Society and The Second Demographic Transition
}

\author{
David R. Hall \\ Department of Sociology \\ Nipissing University \\ North Bay, Ontario, Canada \\ Professional Associate \\ Population Studies Centre \\ University of Western Ontario \\ London, Ontario, Canada
}

\begin{abstract}
Prominent "risk society" theorists such as Giddens and Beck have identified risk as a fundamental organizing principle of contemporary society. Importantly, a major cause of risk awareness and anxiety in modern society is individualism . . a concept Lesthaeghe linked to changes in family formation. In this regard, of the types of risk discussed in the sociological literature, "interpersonal risks" associated with cohabitation, marriage, and parenting are of obvious salience. This paper explores how the modern "risk society" thesis, and the concept of interpersonal risk could materially contribute to understanding the second demographic transition.
\end{abstract}

Key Words: Risk society, second demographic transition, fertility decline 
David R. Hall

\section{Résumé}

Des theorists connu tells que Giddens et Beck qui promeuvent "la société de risqué" ont identifié le risqué comme un principe fundamental de l'organisation de la société contemporaine. De l'importance est que l'individualisme, ... un concept que Lesthaeghe a relié aux changements dans la formation de la famille, est une cause majeuire de la reconnaissance du risqué et de l'anxiété dans la société moderne. En ce qui concerne le risqué, de tous les genres de risqué discutés dans la literature sociologique, les risques "interpersonnels" associés à la cohabitation, le marriage et l'élevement des enfants sont plus communs. Ce papier examine la possibilité que l'idée d'une "société de risqué" moderne, et le concept du risqué interpersonnel pourraient contribuer à la comprehension de la deuxiéme transition démographique.

Key Words: Risk society, second demographic transition, fertility decline

\section{Introduction}

In recent years social demographers have documented a number of remarkable changes in family demographic behavior in the more industrialized and democratic societies. Unprecedented shifts in family formation such as increased cohabitation, divorce, and non-marital fertility, a rising age at first marriage and childbearing, and declining fertility and marriage rates, have been described as a "second demographic transition" by Dirk Van de Kaa (1987) and Ron Lesthaeghe (1995).

While demographers have been successful at tracking and modeling various aspects of the second demographic transition, as a discipline we have been less successful at integrating data, models, and theory on the topic. Indeed, this shortcoming is what led Ron Lesthaeghe to call for a new theoretical approach to the study of family formation (Lesthaeghe, 1998: 7-8). In response to this call, the main purpose of this paper is to examine one of the central concepts derived from the social theory of Anthony Giddens, a concept which, along with others developed by Giddens, could materially contribute to the "overarching" theory of family formation advocated by Lesthaeghe. Specifically, the intent of this paper is to explore the connection between the emergence of "risk" in modern society, and the key trends that characterize the second-demographic transition in Canada. 


\section{The Consequences of Modernity: A Risk Society}

Despite the enormous influence on modern sociological theory of theorists such as Anthony Giddens, demography has been slow to mine his ideas and insights. For instance, in research from Hall (1996), and in the work of Mills (2000), only two of Giddens' concepts on family formation, "plastic sexuality" and "pure relationships", have been applied to the analysis of social demographic phenomenon.

A third key concept from Giddens', which has yet to be adequately applied in social demography, involves the sociological conception of risk found in his work. According to Giddens $(1990 ; 1991)$ one of the major consequences of modernization has been a tremendous intensification of real and perceived or socially mediated risk. Indeed, Giddens (1999) and other prominent sociological theorists such as Ulrich Beck $(1992 ; 1999)$ have described modern society as a risk society! What Giddens and Beck mean by the term risk society is that risk has become strategic organizing principle guiding both individual and institutional thinking and action in contemporary society. Granting that threats and danger have always been a factor in human existence, risk society theorists such as Giddens and Beck maintain that a heightened awareness and knowledge of risk, and sustained effort to manage and contain risk, are defining features of modernity.

\section{Individualism and Risk Society}

While a full discussion of the reasons for the emergence of modern risk society are beyond the scope of this paper, the decline of tradition and formal religion, combined with the rise of globalization, the mass media, individualism, and reflexivity are all implicated. More directly, Giddens (1990) argues that in premodern societies, institutionalized tradition and religion served as crucial social resources for both explaining and coping with threats, tragedies, and uncertainties. As well, in pre-modern societies, most dangers were accepted as things over which humans had little if any control. Instead, these uncertainties and threats were attributed to fate, luck, chance, God's will, and so forth (Beck, 1995:29-33).

Giddens (1999) argues that the erosion of Western tradition and religion, combined with the technological, political-economic, and social change of globalization, has fundamentally altered our appreciation of risk. Instead of viewing most threats as givens, people increasingly understand risks as products of human activities, and as phenomena over which humans exercise control and responsibility. This is true for even far-reaching and potentially catastrophic threats such as those associated with climate change, overpopulation, nuclear war, and terrorism (Beck, 1995:69-72). 
David R. Hall

Put differently, risks and our responses to them, are closely connected to incremental advances in knowledge, the proliferation of mass mediated information, and the individual decision-making that flows from this knowledge and information (Lupton, 1999:17-33). An enhanced awareness or consciousness of risk, therefore, forms an essential part of the background or context in which we move through our everyday lives.

Furthermore, Giddens $(1991 ; 1999)$ attributes our mounting consciousness of risk as a corollary of our focus on anticipating and planning the future. Pursuing this assertion, it is important to note that people have little alternative other than to adopt this "future-orientation" in their lives because contemporary individualism carries with it a growing requirement for individuals to construct and define their own lives independently of stable, mandatory norms, values, or lifestyles. Accordingly, while modern individualism implies freedom to choose from a burgeoning array of social options, individualism also means having to deal with the uncertainty associated with these proliferating options (Beck, Beck-Gernsheim, 2002:1-30). This reciprocal expansion of social choice and social uncertainty is most apparent in the areas of self-identity, work, and the family. Significantly, Wilkinson (2001) argues that these three spheres of everyday life are most likely to engender risk-related anxiety in individuals.

Looked at from a different angle, risk has emerged as a preoccupation in modernity because there are so few aspects of a person's life that follow anything resembling a socially preordained or proscribed path. Instead, the typical individual living in modern society routinely encounters a world of open social possibilities, ambiguity, and contested risk knowledge (Lupton, 1999:65$71)$.

\section{Reflexivity and Risk-Related Anxiety}

In exploring more deeply the issue of how individuals cope with the contingent and open-ended nature of contemporary social existence, risk society theorists highlight the mutually reinforcing processes of reflexivity and risk-based anxiety.

With regard to reflexivity, this process involves a more or less continuous monitoring of the social environment by individuals. More directly, the information and knowledge gained from this monitoring influences subsequent decisions and behaviors by actors. Given that these reflexively-informed decisions and behaviors always, to some extent, modify the actor's social context, reflexivity constitutes a dynamic, feedback response by individuals to uncertainty and risk. Moreover, the greater the potential threats associated with a decision, the more reflexively-informed the decision is likely to be (Lupton, 1999:58-81). 
For example, anyone currently contemplating getting married in Canada will be aware to some extent of the high risk of divorce, of some of the causes and consequences of divorce, and of various other changes affecting the Canadian family. This knowledge will be gleaned through monitoring and evaluating a wide range of information sources including personal experience, official data, and reports from the mass media. Most important, the risk knowledge and awareness will inform a person's decision to marry, delay marrying, or forgo marrying in favor of some perceived less risky alternative such as cohabiting or living single (Giddens, 1990:42-43). It follows that a reflexive knowledge of family-related risks should decisively inform decisions involving familyformation.

Although Giddens' assumes a more or less rational actor whose decisions routinely incorporate risk knowledge, Wilkinson (2001) makes the compelling case that risk awareness involving self and family are likely to cause decisions in these two areas to be strongly influenced by anxiety. Contradicting Lesthaeghe and Surkyn's (1988) thesis that growing individualism reflects a "Maslowian shift" away from satisfying safety and security needs, Wilkinson argues that increasing individualism gives rise to mounting anxiety and a preoccupation with risk reduction, safety, and security (Wilkinson, 2001:6-21).

Empirical support for risk society theory in general, and for Wilkinson's claims in particular, are found in a meta-analysis conducted by Twenge (2000) which documents a substantial rise in anxiety levels among Americans over the past 30 years. Indeed, her study found that anxiety levels from normal population samples now exceed levels of anxiety observed in psychiatric population samples during the 1950s! Even more telling, Twenge's review of the research literature in psychology leads her to conclude that the "social disconnectedness" arising from modern family changes such as rising divorce, declining marriage rates, delayed age at marriage, increased single-living, and diminished childbearing, are responsible for much of the surge in population anxiety levels.

Twenge's findings are relevant because they highlight anxiety as the crucial social psychological link in the causal chain that connects up modern risk society with the second demographic transition. From a psychological perspective, anxiety is understood as an innate fear response by real and potential threats (Spielberger and Rickman, 1990). In particular, the social connectedness model assumes that vulnerability to anxiety will intensify with the diminution of intimate social bonds (Baumeister and Leary, 1995). Hence, the causal relationship between reflexive risk knowledge, risk-based anxiety, and the family changes that characterize the second demographic transition is likely to be self-reinforcing. Paradoxically, as risk awareness and associated anxiety increasingly inform family decision-making, they transform family structure and relationships in ways that intensify awareness of risk and vulnerability to anxiety! 
To recapitulate.risk has steadily shifted on to the individual over the course of modernization, and as a consequence, people are compelled to reflexively assess risks whenever they make important life choices. Indeed, the conception of systemic risk as the salient background or context for family-related decisions can be viewed as a necessary modification of Lesthaeghe's thesis that an ideational shift toward individualism in the west has brought about the second demographic transition (Lesthaeghe and Surkyn, 1988). In a society where less and less can be taken-for-granted, and where everything from tap water and hamburgers, to nuclear weapons and climate change have become popular risk objects, demographers should not be surprised at a theoretical link between transformations in risk and transformations in the family. Indeed, it would be reasonable to expect a powerful, self-validating relationship between changes in risk and changes in the family given that reflexivity and anxiety play a key role in family-decisions and behaviors.

\section{Intimacy in Risk Society: Interpersonal Risk, Pure Relationships and the Post-Familial Family}

Moving beyond risk society theorists such as Giddens and Beck, Deborah Lupton (1999) discusses six general types of risk: environmental (e.g., climate change) lifestyle (e.g., stress), medical (e.g., cancer), interpersonal (e.g., divorce), economic (unemployment), and crime (e.g., terrorism). While there is much overlap in this typology, and, in principle, all of these types could be implicated in the second demographic transition, this study focussed on the type of risk that has the most obvious connection to recent family change in Canada....interpersonal risks, or risks associated with intimate relationships such as cohabitation, marriage, and parenting.

Several scholars have theorized on the risks associated with modern intimacy. For example, employing his ideal type of the "pure relationship", Giddens (1992) has stressed that the essential feature of contemporary cohabitation and marriage is that these relationships are not socially anchored to kinship networks, religion, community, or tradition. Instead, modern pure relationships are reflexively organized by the couple themselves, and serve primarily as "sites" for self-actualization. At the same time, however, these features make intimate relationships inherently unstable, unpredictable and risky.

Likewise, Beck and Beck-Gernsheim (1995; 2002) have described how growing individualism has rendered cohabitation, marriage, parenting, and the family into "empty social categories" or "zombie categories" that couples and their children must "fill", "animate" or create themselves. In particular, individuals who want to live with others in contemporary society must negotiate, define, and justify the characteristics of their relationship on a regular basis. Summarizing 
their latest work, Beck and Beck-Gernsheim (2002) argue that the process of individualization has become more socially relevant as traditional "structuring" institutions such as the family have lost much of their power to mould our behavior and identity. Indeed, the declining number of family-based roles, rules, and models that are taken-for-granted has made even defining the modern family problematic. Rather, the context of current family life is one of indeterminacy and proliferating options (Beck, Beck-Gernsheim, 2002:85-101).

Much like Giddens' pure relationship, Beck and Beck-Gernsheim (2002) conceptualize the "post-familial family" as less a social institution than as a "site" where dynamic social processes such as reflexivity, individualization and risk operate. No longer organized around obligatory norms, values, and roles, the modern family is evolving into an "elective association" of individuals who regularly bring distinctive experiences, interests and goals to the family. Because of this, the viability of modern families turns more and more on their ability to serve as sites that facilitate the self-actualization of family members.

Of course the reflexive organization of the post-familial family attenuates some risks by making families more democratic and egalitarian. However, the indeterminacy and open-ended requirements of the post-familial family amplify other risks and can readily generate novel risks. After all, virtually everything about modern family life, especially the issue of having children, is open to question. With specific reference to childbearing and childrearing, the emergence of the post-familial family has dramatically altered these actions from taken-for-granted family norms and values, into occupational, financial, and existential risks (Beck, Beck-Gernsheim, 2002:101-129). In a larger sense, therefore, families are sites that can provide social support, and sites that can produce risk and anxiety. In short, if risk society theorists such as Giddens, Beck, and Beck-Gernsheim are correct, the contemporary family can serve as a resource for coping with risk and anxiety, and as a source of risk and anxiety (Wilkinson, 2001:87-113).

The dualistic nature of the modern family is exemplified in recent work by Wallerstein, Lewis, and Blakeslee (2000) that detailed the psychosocial risks arising from divorce for couples and especially for their children. More to the point, Wallerstein's highly publicized study on the risks to children of a parental divorce is part of a growing body of research that deals with a mounting variety of risks and anxieties involving parenting.

For example, Lupton (1999) shows how even the earliest stages of parenthood conception and pregnancy - have become heavily infused with risk discourse and meaning. For instance, women who are pregnant or even contemplating pregnancy are commonly advised: to have regular medical examinations and the latest diagnostic tests; to abstain from tobacco and alcohol; to avoid contact with numerous drugs and chemicals; to exercise regularly and appropriately; to maintain a nutritious diet and positive emotional state, and so on. (Lupton, 
1999:59-85). While risk knowledge crucially defines the modern experience and meaning of pregnancy, if anything, parental risk awareness and anxiety increases once the children are actually born.

In addition to the psychosocial risks to children of a parental divorce, Jackson and Scott (1999) have theorized on several other parenting risks which have become more consequential over the years. Among the more prominent sources of parental risk and anxiety that they list are: the perceived ubiquity of pedophiles and sexual predators; random and frequently deadly school-related violence; old and new dangers posed by drugs, teen gangs, adolescent sexuality and AIDS; and various uncertainties concerning educational and career choices for children.

Of course, Giddens (1990; 1992) and Beck, Beck-Gernsheim (2002) contend that parenting poses risks to the parent's ability to self-actualize. As Giddens (1990) has noted, at a minimum having a child can serve as a "drag" on relationship dissolution should one or both partners decide to terminate the cohabitation or marriage. In a broader way, the uncertain, open-ended requirements of modern parenting can materially constrain the ability of individuals, especially women, from "having a life of their own" (Beck, Beck-

Gernsheim, 2002:54-85; 119-129).

For family demographers, the main point to take from this area of sociological theorizing is that parenting has become an activity infused with risk awareness and risk-based anxiety. The manifold choices and indeterminacy of our intimate relationships means that parenting is no longer a taken-for-granted component of adult life or relationships. Instead, children and parenting roles are perceived as risk objects and anxiety sources. As such, childbearing is a decision that requires conscious planning whose major goal is to anticipate and manage the risks and anxieties associated with childrearing.

On the strength of these theoretical insights on the transformation of risk in modern society, the following hypotheses were derived in order to empirically assess the connection between the emergence of a "risk society" and the key family trends that define the second demographic transition. 


\section{Hypotheses}

(1) All else the same, the more risk that individuals associate with intimate relationships, the more likely they are to favor cohabitation. The assumption is that cohabitation is widely regarded as a means for mitigating interpersonal risks and related anxiety associated with intimate relationships.

(2) All else the same, the more risk that individuals associate with intimate relationships, the more likely they are to favor an older age at entry into these relationships. The assumption in this hypothesis is that a higher age at cohabitation and marriage is a useful way of reducing, or at least postponing, the interpersonal risks associated with forming a cohabitational or marital union.

(3) All else the same, the more risk that individuals associate with intimate relationships, the lower their fertility intentions will be. This hypothesis assumes that minimizing fertility is perceived by most people as an effective way of minimizing interpersonal risk and related anxiety.

(4) All else the same, higher parenting risk will be associated with lower fertility intentions. The assumption underlying this hypothesis is that most people will view reduced fertility as a strategy for reducing the parenting dimension of interpersonal risk.

\section{Data and Methods}

A major problem with empirically evaluating new theoretical ideas is the dearth of relevant data. Scientific inquiry must begin somewhere, however, so in order to generate useful data, a survey was developed and administered to a convenience sample of 251 sociology undergraduates at Nipissing University during the fall of 2001. In terms of demographic traits, the sample was comprised mainly of single, female, university students between 20 and 23 years of age. Obviously, with such a small and unrepresentative sample, the goal of the study was not to construct and test a fully-specified and generalizable model. Instead, the goal of the research was to operationalize interpersonal risk in order to gain preliminary insights into any empirical association between intepersonal risk knowledge and indicators of family demographic change.

For analytic purposes, interpersonal risk was designated the independent variable, and a total of 40 questions on the survey were developed in an effort to measure this variable. A total of of five dimensions of interpersonal risk emerged from a purely exploratory factor analysis of the data, and Table 1 shows the survey questions whose values were summed to form an index measuring the first dimension which was labeled relationship risk or Relrisk. 
With the growing importance of cohabitation as a first union experience among younger Canadians, it was felt that more meaningful responses to relationship risk questions could be obtained from this sample by asking questions about common-law rather than marital relationships. Presumably, a higher score on the Relrisk index translates into a higher risk that a respondent's current or future common-law relationship will be dissolved.

The second risk index operationalized the dimension of pregnancy risk, and was formed by adding up the responses to the questionnaire items listed in Table 2. These items captured respondent agreement with statements on several pregnancy risks.ranging from the need to abstain from alcohol and tobacco, to the importance of medical intervention and surveillance to assure the health of the mother and fetus. Although the responses suggested considerable risk knowledge in the sample of all the pregnancy risks, smoking while pregnant and the need to see a physician regularly to monitor health of mother and fetus received the highest levels of agreement. The second summed index was called Pregrisk.

Looking at Table 3, the questionnaire items in this table measured a dimension that has been termed exogenous parenting risks or Exorisk. In attempting to put together reliable and content valid indices, two sets of risks associated with parenting emerged from the data...exogenous parenting risks and endogenous parenting risks. The exogenous parenting risk index shown in Table 3 consists of risk indicators that are notable by the extent to which these hazards are culturally or socially mediated. More directly, a respondent's perception of the threat posed from pedophiles, drugs and alcohol, or school violence is likely to be heavily influenced by political agendas and consumption of the mass media. To illustrate, as of this writing the Canadian government has announced an advertising and public education campaign designed to combat school bullying in the wake of extensive media coverage of this phenomenon over the past year. It is worth noting that over one-half of the study group strongly agreed with the statement that "Eating disorders are a serious and growing problem for children and teenagers".... a finding that probably reflects the predominantly young and female composition of the convenience sample.

On the other hand, Table 4, lists what were called endogenous parenting risks or Endrisk. These items deal with risks that appear more intrinsic to the modern parenting role. For instance, the survey questions summed to create this index included statements on the vital role of parents in assuring their children's educational achievement, and on parental responsibility for their children's actions until the latter reach adulthood. Interestingly, in the study sample the strongest agreement was given for the importance of parents in contributing to their child's educational success and for monitoring their child's television viewing. 
Table 1

Percentage Distribution of Relationship Risk Indicators

Nipissing University, 2001

The list below covers various reasons that people give for ending a common-law relationship. For each of the reasons listed below, please indicate how important YOU would regard them as reasons for splitting up a common-law relationship.

\begin{tabular}{|c|c|c|c|}
\hline & $\begin{array}{c}\text { very } \\
\text { important } \\
\end{array}$ & $\begin{array}{l}\text { somewhat } \\
\text { important }\end{array}$ & $\begin{array}{c}\text { not } \\
\text { important } \\
\end{array}$ \\
\hline Alcohol and/or drug abuse by partner & 80 & 18 & 2 \\
\hline Lack of love by partner & 86 & 14 & 0 \\
\hline Lack of respect by partner & 85 & 12 & 1 \\
\hline $\begin{array}{l}\text { Inability to agree with partner } \\
\text { on household finances }\end{array}$ & 28 & 61 & 11 \\
\hline $\begin{array}{l}\text { Partner refuses to do their fair share of } \\
\text { the housework }\end{array}$ & 18 & 62 & 20 \\
\hline Partner is unfaithful & 89 & 10 & 1 \\
\hline $\begin{array}{l}\text { Sexual relationship with partner } \\
\text { is unsatisfactory }\end{array}$ & 15 & 67 & 19 \\
\hline $\begin{array}{l}\text { Not enough common interests } \\
\text { with partner }\end{array}$ & 21 & 60 & 19 \\
\hline $\begin{array}{l}\text { Inability to get along with partner's } \\
\text { friends and/or relatives }\end{array}$ & 11 & 63 & 29 \\
\hline $\begin{array}{l}\text { Partner does not support you in } \\
\text { achieving your own goals }\end{array}$ & 61 & 33 & 6 \\
\hline
\end{tabular}

Descriptive Statistics for Relationship Risk (relrisk) Index:

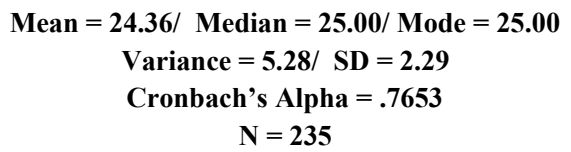


Table 2

Percentage Distribution of Pregnancy Risk Indicators

Nipissing University, 2001

This section consists of statements regarding various family-related issues. Please indicate your level of agreement with each statement by circling the most appropriate number. (For example, circling the number $\underline{5}$ would indicate that you strongly agree with the statement, while circling the number $\underline{1}$ would indicate that you strongly disagree with the statement, and so forth).

\begin{tabular}{lccccc}
\hline & $\begin{array}{c}\text { strongly } \\
\text { disagree }\end{array}$ & disagree & unsure & agree & $\begin{array}{c}\text { strongly } \\
\text { agree }\end{array}$ \\
\hline \hline Once a woman becomes pregnant, & & & & &
\end{tabular}

she should carefully watch her diet

to ensure proper nutrition for the fetus

0

1

9

32

58

A pregnant woman should take care to avoid

exposure to second-hand cigarette smoke

1

2

10

35

52

A pregnant woman needs to see her doctor regularly throughout the pregnancy to monitor her health as well as the health of the fetus 0

1

6

18

75

Most pregnant women should have medical tests to ensure the health of the fetus

$\begin{array}{lllll}0 & 3 & 11 & 36 & 50 \\ 1 & 1 & 3 & 15 & 80 \\ 1 & 4 & 13 & 20 & 62\end{array}$

A woman should never smoke while pregnant

While pregnant, a woman should not drink alcohol

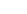

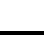

13

Descriptive Statistics for Pregnancy Risk (pregrisk ) Index:

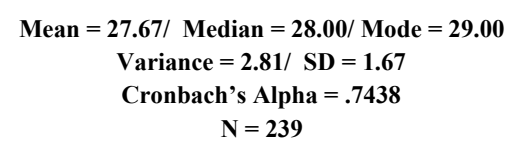


Table 3

Percentage Distribution of Exogenous Parenting Ris Indicators

Nipissing University, 2001

This section consists of statements regarding various family-related issues. Please indicate your level of agreement with each statement by circling the most appropriate number. (For example, circling the number $\underline{5}$ would indicate that you strongly $\underline{\text { agree }}$ with the statement, while circling the number $\underline{1}$ would indicate that you strongly disagree with the statement, and so forth).

\begin{tabular}{|c|c|c|c|c|c|}
\hline & $\begin{array}{r}\text { strongly } \\
\text { disagree }\end{array}$ & disagree & unsure & agree & strongly agree \\
\hline $\begin{array}{l}\text { Pedophiles and child molesters are } \\
\text { more of a threat than ever before. }\end{array}$ & 3 & 10 & 36 & 29 & 22 \\
\hline School violence is getting worse over time. & 1 & 8 & 12 & 48 & 31 \\
\hline $\begin{array}{l}\text { Eating disorders are a serious and growing } \\
\text { problem for children and teenagers. }\end{array}$ & 1 & 1 & 9 & 37 & 52 \\
\hline $\begin{array}{l}\text { Alcohol and illegal drug use among young } \\
\text { people jeopardizes their lives. }\end{array}$ & 3 & 11 & 20 & 43 & 23 \\
\hline $\begin{array}{l}\text { It is very important to "streetproof" } \\
\text { children in order to protect them from harm. }\end{array}$ & 1 & 3 & 10 & 44 & 42 \\
\hline
\end{tabular}

Descriptive Statistics for Exogenous Parenting Risk ( exorisk ) Index:

\author{
Mean $=20.72 /$ Median $=21.00 /$ Mode $=19.00$ \\ Variance $=6.23 / \mathrm{SD}=\mathbf{2 . 4 9}$ \\ Cronbach's Alpha $=\mathbf{. 6 8 1 0}$ \\ $\mathbf{N}=\mathbf{2 3 7}$
}


Table 4

Percentage Distribution of Endogenous Parenting Risk Indicators Nipissing University, 2001

This section consists of statements regarding various family-related issues. Please indicate your level of agreement with each statement by circling the most appropriate number. (For example, circling the number $\underline{5}$ would indicate that you strongly agree with the statement, while circling the number 1 would indicate that you strongly disagree with the statement, and so forth).

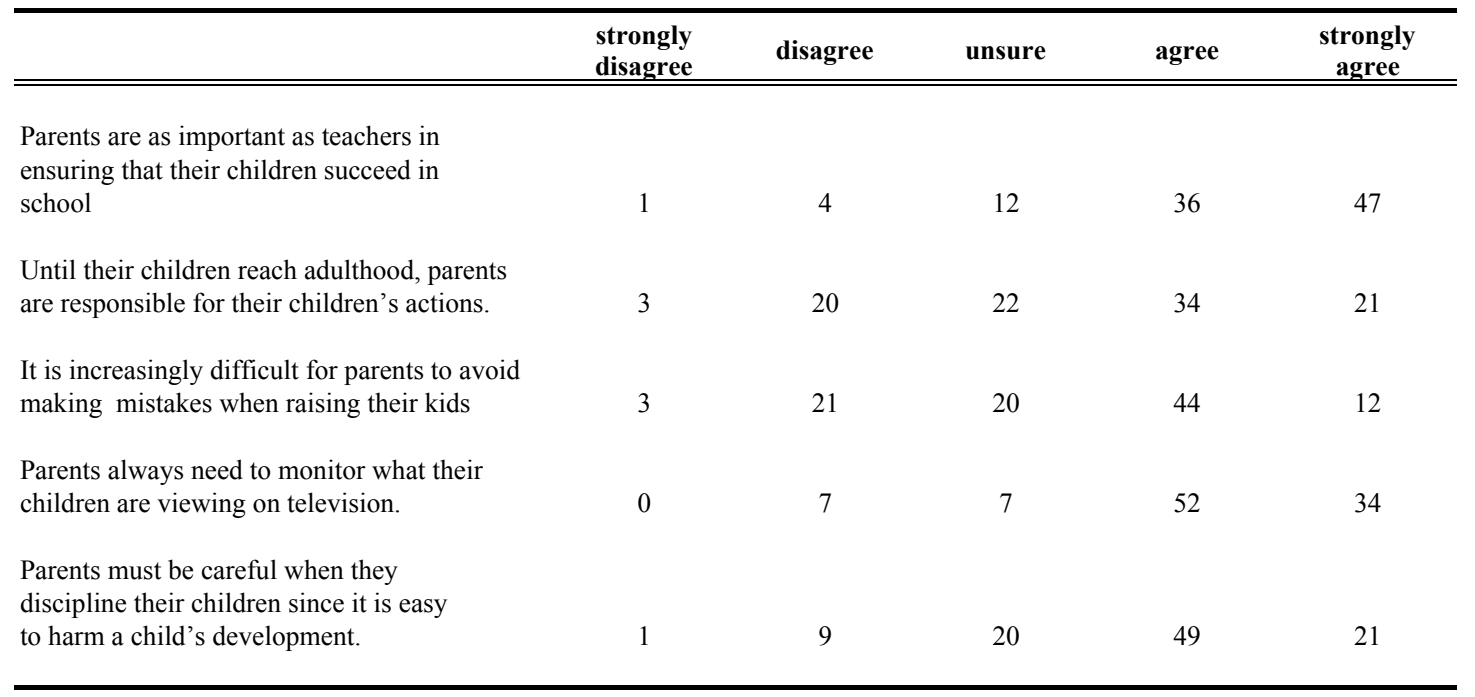

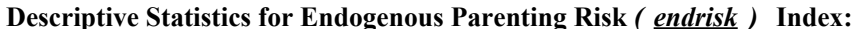

Mean $=19.63 /$ Median $=19.00 /$ Mode $=19.00$

Variance $=\mathbf{5 . 0 7 /} \mathrm{SD}=\mathbf{2 . 2 5}$

Cronbach's Alpha $=.6756$

$\mathbf{N}=\mathbf{2 3 9}$ 
Finally, it is worth reiterating that risk is not only associated with doing something, but risk can also arise from NOT doing something. Accordingly, questionnaire items were developed that measured the obvious risks from NOT having children. Overall, in the study group there was little agreement with the notion that childless couples have less stable relationships than couples with children. On the other hand, over half of the sample agreed or strongly agreed with the idea that having children will have no negative effects on their careers. In any case, the four items in Table 5 combined to form an index that operationalized this dimension of interpersonal risk and the index was called Nonrisk.

On balance, this first attempt at operationalizing interpersonal risk was a valuable exercise. Although 10 of the survey items turned out to be unusable, the responses to the remaining 30 survey questions were combined into five simple additive indexes with minimally acceptable reliability levels.

Turning our attention to the dependent variables, Table 6a provides the percentage distribution and descriptive statistics for intended fertility, while Table $6 \mathrm{~b}$ shows the descriptive statistics for other key demographic indicators measured in the survey. The tables require little elaboration other than to review the dependent variables in the study which were: intended fertility, ideal age for a man to cohabit, ideal age for a woman to cohabit, ideal age for a man to marry, ideal age for a woman to marry, respondent approval of common-law unions where the couple have no intention of marrying, and respondent approval of common law couples having children when the couple have no intention of marrying. While not exhaustive, these variables all reflect demographic changes that characterize the second demographic transition.

\section{Results and Conclusion}

Table 7 summarizes the results of a series of standard multiple regressions which were conducted in order to empirically test the hypotheses. Obviously, given the nature and characteristics of the sample, and the limited empirical scope of the project, the goal was simply to determine if a relationship existed between the indicators of interpersonal risk and of family demographic change. As an interesting aside, of the five indices, only pregrisk was substantially skewed. The other four indixes were more or less normally distributed. Further, regression diagnostics revealed that multicollinearity was not a serious problem among the independent variables. 
Table 5

Percentage Distribution of Non-Parenting Risk Indicators Nipissing University, 2001

This section consists of statements regarding various family-related issues. Please indicate your level of agreement with each statement by circling the most appropriate number. (For example, circling the number $\underline{5}$ would indicate that you strongly agree with the statement, while circling the number 1 would indicate that you strongly disagree with the statement, and so forth).

\begin{tabular}{|c|c|c|c|c|c|}
\hline & $\begin{array}{l}\text { strongly } \\
\text { disagree }\end{array}$ & disagree & unsure & agree & $\begin{array}{c}\text { strongly } \\
\text { agree }\end{array}$ \\
\hline $\begin{array}{l}\text { Childless couples have less stable } \\
\text { relationships than couples with children. }\end{array}$ & 19 & 44 & 21 & 10 & 6 \\
\hline $\begin{array}{l}\text { Having a child increases the quality of a } \\
\text { couple's relationship. }\end{array}$ & 6 & 26 & 33 & 29 & 6 \\
\hline $\begin{array}{l}\text { Family law reforms ensure that divorced } \\
\text { parents can obtain adequate child-support } \\
\text { payments from their ex-spouses }\end{array}$ & 6 & 16 & 42 & 27 & 9 \\
\hline $\begin{array}{l}\text { For most women, having children will have } \\
\text { no negative effects on their careers. }\end{array}$ & 7 & 19 & 22 & 42 & 10 \\
\hline
\end{tabular}

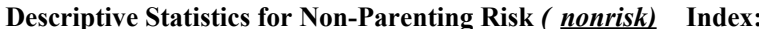

Mean $=11.80 /$ Median $=12.00 /$ Mode $=11.00$
Variance $=4.49 /$ SD $=2.12$
Cronbach's Alpha $=.6304$
N $=238$


To begin with, the multiple correlation coefficients show that interpersonal risk was most successful in accounting for variations in intended fertility, ideal age to marry for men and women, and approval of childbearing within common-law unions. The risk indices explained minimal variability in the ideal age for cohabiting, and in respondent approval of living common-law with no intent to marry.

Focussing on model 1 , which regressed intended fertility on the five risk indices, the strongest negative predictor of fertility was Relrisk or the index measuring the risk of relationship dissolution. This was followed by Exorisk which captured exogenous parenting risks. On the other hand, the Nonrisk index that measured the risks of forgoing childbearing had the strongest positive link to intended fertility. Surprisingly, the pregrisk index was also positively associated with intended fertility. Net of the other risk indices, each unit increase in the pregrisk index produced an increase of .164 in intended fertility.

However, because there is so little variation in intended fertility, this is a substantial positive impact. Overall, while the results of model 1 were consistent with hypothesis 3 , hypothesis 4 received only qualified support from this regression. Indeed, heightened sensitivity to pregnancy risks is connected to higher rather than lower intended fertility... an unexpected finding that hints at a more complex relationship between risk and fertility intentions than originally envisioned.

Moving on to model 3 and model 5, which regressed the indices on the ideal age for men and women to marry, there was consistency in the results with relrisk, pregrisk, and endrisk having noteworthy effects in both models. As hypothesis 2 stated, a higher risk of relationship dissolution was associated with a higher ideal age at marriage for both sexes... and given the distribution of this variable the impact was not trivial. Meaningful coefficients between the pregnancy and parenting risk indexes and ideal age at marriage were not anticipated. Accordingly, the finding that changes in Pregrisk and Endrisk do produce changes in age at marriage, but not in age at cohabitation, implies that parenting remains more embedded in marital than in common-law unions. It is worth mentioning that Pregrisk and Endrisk produced opposite effects on the dependent variable,.with higher Pregrisk scores producing a lower age at marriage, while higher Endrisk scores produced a higher ideal marriage age.

Further evidence to support a stronger link between parenting and marriage can be seen in model 7, which regressed the five indices on respondent approval of common law couples having children when the couple have no intention of marrying. Consistent with hypothesis 1 , a unit increase in the Relrisk index produced a moderately large jump in respondent approval. Also, both the Nonrisk and Pregrisk indexes were inversely associated with respondent approval. In the case of the coefficient for Nonrisk, there is empirical support for hypothesis 1. 
Table 6a

Fertility Intentions, Nipissing University, 2001

\begin{tabular}{lcc}
\hline $\begin{array}{c}\text { Number of Children Respondent } \\
\text { intends to have }\end{array}$ & Frequency & Percentage \\
\hline \hline & 14 & 6 \\
None & 31 & 13 \\
One & 102 & 42 \\
Two & 71 & 30 \\
Three & 19 & 8 \\
Four & 2 & 1 \\
Five or more & & 100 \\
& 239 & \\
\hline
\end{tabular}

1 Open-ended question on survey was "How many children do you intend to have? (Please include any children that you already have)

Table 6b

Descriptive Statistics for Other Demographic Variables Nipissing University, 2001

\begin{tabular}{lll}
\hline \multicolumn{1}{c}{ Variable } & Mean & S.D. \\
\hline \hline $\begin{array}{l}\text { Ideal age for a woman to enter } \\
\text { a common-law union. }\end{array}$ & & \\
$\begin{array}{l}\text { Ideal age for a man to enter a } \\
\text { a common-law union. }\end{array}$ & 21.88 & 2.29 \\
$\begin{array}{l}\text { Ideal age for a woman to marry. }{ }^{2} \\
\text { Ideal age for a man to marry. }\end{array}$ & 22.46 & 2.47 \\
$\begin{array}{l}\text { Approve of living common-law if couple } \\
\text { has no intention of getting married. }\end{array}$ & 24.41 & 1.63 \\
$\begin{array}{l}\text { Approve of common-law couple having } \\
\text { children if couple has no intention of } \\
\text { getting married. }\end{array}$ & 25.09 & 1.99 \\
\hline
\end{tabular}

${ }^{1}$ Open-ended survey question was "Ideally, how old do you think a woman should be before entering a common-law relationship?"

${ }^{2}$ Open-ended survey question was "Ideally, how old do you think a woman should be before she gets married?"

${ }^{3}$ Response categories ranged from 1 (Completely Disapprove) to 7 (Completely Approve).

${ }^{4}$ Response categories ranged from 1 (Completely Disapprove) to 7 (Completely Approve). 
Table 7

Multiple Regression of Risk Indices on Second Demographic Transition Indicators Nipissing University, 2001

\begin{tabular}{|c|c|c|c|c|c|c|c|}
\hline \multirow[b]{2}{*}{$\begin{array}{c}\text { Independent } \\
\text { Variables } \\
\end{array}$} & \multicolumn{6}{|c|}{ Regression Coefficients (Unstandardized) } & \multirow[b]{2}{*}{ Model 7g } \\
\hline & Model 1a & Model 2b & Model 3 c & Model $4 \mathrm{~d}$ & Model 5 e & Model 6f & \\
\hline \multicolumn{8}{|l|}{$\underline{\text { Risk Indices }}$} \\
\hline RELRISK & -0.125 & 0.057 & 0.268 & 0.077 & 0.247 & 0.19 & 0.225 \\
\hline PREGRISK & 0.164 & -0.017 & -0.256 & -0.021 & -0.198 & -0.019 & -0.135 \\
\hline EXORISK & -0.115 & 0.238 & 0.028 & 0.188 & 0.02 & 0.021 & 0.096 \\
\hline ENDRISK & -0.004 & 0.021 & 0.173 & 0.036 & 0.21 & 0.033 & -0.008 \\
\hline NONRISK & 0.127 & 0.048 & -0.092 & 0.04 & -0.145 & -0.289 & -0.213 \\
\hline $\mathbf{R}=$ & 0.627 & 0.263 & 0.497 & 0.289 & 0.549 & 0.403 & 0.512 \\
\hline Square $=$ & 0.393 & 0.069 & 0.247 & 0.084 & 0.301 & 0.162 & 0.262 \\
\hline
\end{tabular}

${ }^{a}$ Dependent variable is intended fertility.

${ }^{\mathrm{b}}$ Dependent variable is ideal age for men to cohabit.

${ }^{c}$ Dependent variable is ideal age for men to marry.

${ }^{\mathrm{d}}$ Dependent variable is ideal age for women to cohabit.

${ }^{\mathrm{e}}$ Dependent variable is ideal age for women to marry.

${ }^{\mathrm{f}}$ Dependent variable is approval of common-law unions with no intent to marry.

${ }^{\mathrm{g}}$ Dependent variable is approval of common-law couples having children when the couple have no intent to marry. 
In contrast, model 2 and model 4, regressed the indices on ideal age at cohabitation provided little evidence in support of hypothesis 1 . Not only did the measures of interpersonal risk collectively explain hardly any of the variance in the dependent variable, but the only non-trivial predictor was the Exorisk index. The peculiar effect of exogenous parenting risk on age at cohabitation suggests that the former may be capturing a deeper risk-related anxiety than is captured in the indicators. More important, changes in relationship risk produced no discernable change in age at cohabitation.

In view of the theoretical thrust of this study, and major limitations of data collected from the convenience sample, the central conclusion flowing from this study is that the sociological concepts of risk and risk-based anxiety give social demographers a new and promising set of tools for analyzing and explaining contemporary family demographic change. Clearly, the conceptual and operational definitions of interpersonal risk, and of other potentially salient types of risk such as economic and lifestyle risks, need to be developed and refined. Moreover, the potentially self-reinforcing relationship between heightened risk awareness, anxiety and reflexive family decisions must be formalized and modeled using larger, representative samples. After all, only with larger, representative samples can fully specified risk models be tested that enable researchers to ascertain the substantive and statistical significance of risk and anxiety while controlling for key demographic variables such as age, gender, and education. Finally, even though the ideas of Giddens, Beck, and other sociologists can contribute a great deal to social and family demography, insights from other disciplines such as social psychology and economics will almost certainly be needed in order to adequately theorize the relationship between the emergence of modern risk society and the second demographic transition.

\section{Acknowledgements:}

An earlier version of this paper was presented at the annual meetings of the Canadian Population Society, Quebec City, Quebec, May 27-29, 2001. Please direct all correspondence to David Hall, Department of Sociology, Nipissing University, North Bay, Ontario, P1B 8L7 Canada.

Support for this project was provided by the Office of Research at Nipissing University and a Social Sciences and Humanities Research Council of Canada Start-Up Research Grant. The author is grateful to Cher Harvey, Susan Cardy, and two anonymous reviewers for their assistance with this paper. 


\section{References:}

Baumeister, R. F. and M. R. Leary. 1995. "The need to belong: Desire for interpersonal attachments as a fundamental human motivation," Psychological Bulletin, 117: 497-529.

Beck, U. 1992. Risk Society: Towards a New Modernity. London: Sage.

Beck, U. 1995. Ecological Politics in the Age of Risk. Cambridge: Polity Press.

Beck, U. 1999. World Risk Society. Cambridge: Polity Press.

Beck, U. and E. Beck-Gernsheim. 1995. The Normal Chaos of Love. Cambridge: Polity Press.

Beck, U., and E. Beck-Gernsheim, 2002. Individualization. London: Sage.

Beck, U. "Living your life in a runaway world," in A. Giddens and Will Hutton (eds.) 2000. On the Edge: Living with Global Capitalism. London: Random House. Pp.164-174.

Giddens, A. 1990. The Consequences of Modernity. Stanford: Stanford University Press.

Giddens, A. 1991. Modernity and Self-Identity. Stanford: Stanford University Press.

Giddens, A. 1992. The Transformation of Intimacy. Stanford: Stanford University Press.

Giddens, A. 1999. Runaway World: How Globablization is reshaping our lives. London: Profile Books.

Hall, D. R. 1996. "Marriage as a pure relationship: exploring the link between premarital cohabitation and divorce in Canada," Journal of Comparative Family Studies 27(1): 1-12.

Jackson, S., and S. Scott. "Risk anxiety and the social construction of childhood," in D. Lupton (ed.) Risk and Sociocultural Theory. Cambridge: University Press. Pp. 86-107,

Lesthaeghe, R., and J. Surkyn. 1988. "Cultural dynamics and economic theories of fertility change," Population and Development Review 14(1): 1-45. 
David R. Hall

Lesthaeghe, R. 1998. "On theory development: applications to the study of family formation," Population and Development Review 24(1): 1-14

Lesthaeghe, R. 1995. "The second demographic transition in Western countries: An interpretation," in K. O. Mason and A. M. Jensen (eds.) Gender and Family Change in Industrialized Countries. New York: Oxford University Press. Pp. 7-62.

Lupton, D. 1999. Risk. London: Routledge.

Lupton, D. 1999b. "Risk and the ontology of pregnant embodiment," in D. Lupton (ed.) Risk and Sociocultural Theory. Cambridge: University Press. Pp. 59-85.

Mills, M. 2000. The Transformation of Partnerships. Amsterdam: Theia Thesis Population Studies Series.

Spielberger, C. D. and R. I. Rickman. 1990. "Assessment of state and trait anxiety," in N. Sartorius, V. Andreoli, G. Cassano, L. Eisenberg, P. Kielkolt, P. Pancheri, and G. Racagni (eds.) Anxiety: Pyschobiological and Clinical Perspectives. New York: Hemisphere Publishing. Pp. 69-83,

Twenge, J. M. 2000. "The Age of Anxiety? Birth Cohort Change in Anxiety and Neuroticism," Journal of Personality and Social Psychology 79(6): 1007-1021.

Van De Kaa, D. J. 1987. "Europe's Second Demographic Transition," Population Bulletin 42(1): 1-59.

Wallerstein, J., J. Lewis, and S. Blakeslee. 2000. The Unexpected Legacy of Divorce. New York: Hyperion.

Wilkinson, I. 2001. Anxiety in a Risk Society. New York: Routledge. 